\title{
Attitudes Toward Cardiovascular Disease Risk Factors Among Patients Referred to a Cardiac Rehabilitation Center: Importance of Psychological Attitudes
}

\author{
Mozhgan Saeidi ${ }^{1}$; Ali Soroush ${ }^{2}$; Saeid Komasi ${ }^{1, *}$; Khodamorad Moemeni ${ }^{3}$; Behzad \\ Heydarpour ${ }^{1}$ \\ ${ }_{2}^{1}$ Cardiac Rehabilitation Center, Imam Ali Hospital, Kermanshah University of Medical Sciences, Kermanshah, IR Iran \\ ${ }_{2}^{2}$ Department of Sports Medicine and Rehabilitation, Imam Reza Hospital, Kermanshah University of Medical Sciences (KUMS), Kermanshah, IR Iran \\ ${ }^{3}$ Department of psychology, Kermanshah Razi University, Kermanshah, IR Iran \\ ${ }^{*}$ Corresponding Author: Saeid Komasi, Cardiac Rehabilitation Center, Imam Ali Hospital, Kermanshah University of Medical Sciences. Kermanshah, IR Iran. Tel: +98-8334294910; +98- \\ 9185726991, E-mail:s_komasi63@yahoo.com
}

Received: August 25, 2013; Revised: March 7, 2014; Accepted: April 12, 2014

\begin{abstract}
Background: Patients' understanding of heart diseases and their related experiences can affect education and prevention of coronary heartdiseases. As the patients' beliefs play a crucial role in the development of effective therapeutic relationship, psychological adjustment, and compliance with treatment recommendations.

Objectives: The purpose of this study was to investigate the attitudes toward psychological risk factors for cardiovascular disease among patients referred to a cardiac rehabilitation center in Imam Ali Hospital in Kermanshah, Iran.

Patients and Methods: This cross-sectional study was performed on 775 patients referred to a cardiac rehabilitation unit in Imam Ali hospital in Kermanshah, Iran. Data were collected using clinical interview, patients' medical records, and Millon clinical multiaxial inventory (MCMI-III), and analyzed by descriptive statistics, including mean, standard deviation, and chi - square test. Statistical analyses were performed using SPSS software version 18.

Results: The patients believed that the main cause of their illness is behavioral risk factors (42.0\%). Then, they referred to psychological (36.3\%), biological (4.3\%), and environmental (3.8\%) factors, respectively. $10.4 \%$ of the patients were not aware of the cause of their illness. Also, stress is the most important factor among the psychological factors (27.5\%). The results showed that there was a significant difference among the patients in term of four attitudes $\left(\chi^{2}=820.356 ; \mathrm{P}<0.01\right)$; and behavioral and psychological attitudes $\left(\chi^{2}=6.025 ; \mathrm{P}<0.05\right)$. In fact, the patients identified behavioral problems as the main cause of their illness.

Conclusions: According to the patients' attitudes, after the behavioral factors, psychological factors are the second cause of heart diseases. Therefore, ignoring these factors by members of the medical teams may lead to a poor performance of the treatments. As these factors are controllable, learning to control and manage them can prevent the development of subsequent cardiovascular events.
\end{abstract}

Keywords: Cardiovascular disease; Psychological; Risk Factors; Patients; Attitudes; Cardiac Rehabilitation; Heart Disease

\section{Background}

Cardiovascular diseases (CVD) are the leading cause of mortality worldwide, and it is responsible for more than seventeen million deaths annually around the world. Almost eighty percent of these deaths occur in the less developed countries (1). According to a research (2), about 15 million people in Iran are suffering from heart diseases. In 2007, among one hundred thousand cases, suffering from heart diseases reported in Iran, 167 of them died. It shows a high mortality rate in cardiac patients (2).

Today, millions of people are unknowingly exposed to various risk factors associated with CVD that they themselves are not aware of them (3). These risk factors can be divided into several categories including biological, environmental, behavioral, and psychological risk factors (4). Biological factors include age, gender, family history, and hereditary hyper-cholesterolemia. Environmental factors are as follows: smoking, water and air pollution, toxic substances, and dust. Behavioral factors include smoking, drugs, inactivity, poor nutrition, diabetes, hypertension and obesity (5). The fourth category is psychological risk factors which consist of anxiety, depression, anger, aggression, personality types, grief, and stress can have an important role in causing heart diseases $(4,6)$. This paper aimed to emphasize the psychological risk factors and their impacts on the progression of heart diseases.

Psychological factors, affecting cardiovascular events, may play an important role in chronic biological phenomena which lead to heart diseases like circadian, weekly or seasonal patterns. The chronic role of psycho-

Copyright ( 2015, Shiraz University of Medical Sciences. This is an open-access article distributed under the terms of the Creative Commons Attribution-NonCommercial 4.0 International License (http://creativecommons.org/licenses/by-nc/4.0/) which permits copy and redistribute the material just in noncommercial usages, provided the original work is properly cited. 
logical factors, such as stress on atherosclerosis, and the long-term cardiovascular disorders have been studied. This evidence suggests that everyday situations and activities, with psychological stress, are primarily related to sudden cardiac events (2).

Psychological factors due to the impact that can have on the cardiac patients' mood may have influence on their attitude of causes of illness (7). As the patients' health is related to behaviors rooted in their knowledge (8), their beliefs about CVD have a decisive role in their health behavior (9). Cognitions and beliefs of patients have a significant impact on the course and progression of all the phases of the disease experience including understanding the signs, looking for causes, and changes in individual behavior (8). How patients understand a CVD, its impact on the education and prevention of coronary heart disease (10), and beliefs of the patient play a crucial role in effective treatment relationships, psychological adjustment and adherence to treatment recommendations (11), which will facilitate the acceptance of psychological interventions (7). Studies show that patients' beliefs about angina are associated with psychological and functional status of these patients. Patients with more myths are more anxious and have lower physical function than the other patients (12).

Although some studies indicate a small relationship between actual and perceived risk factors in patients (13), other studies show a strong relationship between patients' causal beliefs about CVD and its risk factors $(14,15)$. In this regard, the role of psychological factors from the patients' perspectives is undeniable (16). Astin and Jones (17) found that women identified stress as the main cause of their illness, while men identified it as the third cause of their illness after eating and smoking. Although the study by Perkins-Porras (14) did not explore a significant role for the psychosocial risk factors among patients' beliefs, based on other studies, patients view worry, depression and anxiety as psychological risk factors (18). Patients' beliefs, like stress, are related to both the current mood of the patients and their stressful life (14). Patients believe that stress is a major cause of CVD and should always be avoided (19).

However, so far no study has been done on comparison of heart disease risk factors from the patients' perspective. Furthermore, given that attitude of patients about causes of their illness can be associated with their mental health directly.

\section{Objectives}

The purpose of this study was to evaluate the attitudes toward psychological risk factors for cardiovascular disease among patients referred to a cardiac rehabilitation center in Imam Ali Hospital in Kermanshah, Iran.

\section{Patients and Methods}

In the present study, a cross-sectional design was ap- plied. The study population consisted of 831 cardiac patients, who were referred to the cardiac rehabilitation center of Imam Ali hospital during 2010 - 2013 in Kermanshah, Iran. An inclusion criterion was to be younger than 85 years. Therefore, 55 patients were excluded from the study due to either aging or lack of cooperation. Finally, 775 patients were included in the study sample. Data were collected using clinical interviews, patients' medical records and Millon clinical multiaxial inventory (MCMI-III). In this study, patients' attitudes were grouped into one of the four categories of heart disease risk factors including biological, environmental, behavioral, and psychological factors. Thus, upon arrival of the patients in the rehabilitation process, these risk factors were questioned by a clinical psychologist in this section about the occurrence causes of heart disease from the perspective of the patients, in a clinical interview. Then, she recorded in the patient's medical history the data obtained in the field, along with demographic characteristics and their records. Finally, for data analysis, descriptive statistics including mean, standard deviation, percent, and chisquare test were calculated, using SPSS version 18.

Furthermore, Millon test was used to evaluate comorbidities in the patients. The Millon clinical multiaxial inventory (MCMI-III) is an assessment tool used to provide clinicians with information related to a patient's psychopathology. This includes the diagnosis for any personality disorder detailed in the The fourth edition of diagnostic and statistical manual of mental disorders DSM-IV-TR. This assessment is intended only for individuals over the age of 18 and who possess a minimum reading level equivalent to the eighth grade. The MCMI-III is a 175-item, true-false self-report psychological inventory related to an individual's psychopathology and used with emotionally disturbed patients (20). Test-retest studies for the MCMI-I showed good stability and produced reliability coefficients ranging from 82 for the Debasement scale to .90 for the Somatoform scale (21). Similarly, it was found that scores were comparable to samples of substance abusers. Further, correlations tend to be higher for the personality scales versus the clinical syndromes. This is, in part, due to the fact that personality characteristics are more enduring whereas clinical symptoms are more transient (21). Finally, results of Blais et al. (2003) suggest that the MCMI-III validity is appropriate and it was found to demonstrate appropriate convergent and divergent validity with other self-report measures (22).

\section{Results}

The participants of the study consisted of 775 patients (256 females; 519 males). The mean ( \pm SD) age of the participants was $58.26 \pm 9.10$ in total, $58.89 \pm 8.29$ in women, and $57.95 \pm 9.46$ years in men. In addition, age range was 29 - 82 years in total, 29 - 78 in women, and 31 - 82 years in men. Patients' socio-demographic characteristics have been indicated in Table 1. Also, this Table shows the rates of comorbidities in the cardiac patients. 
Saeidi M et al.

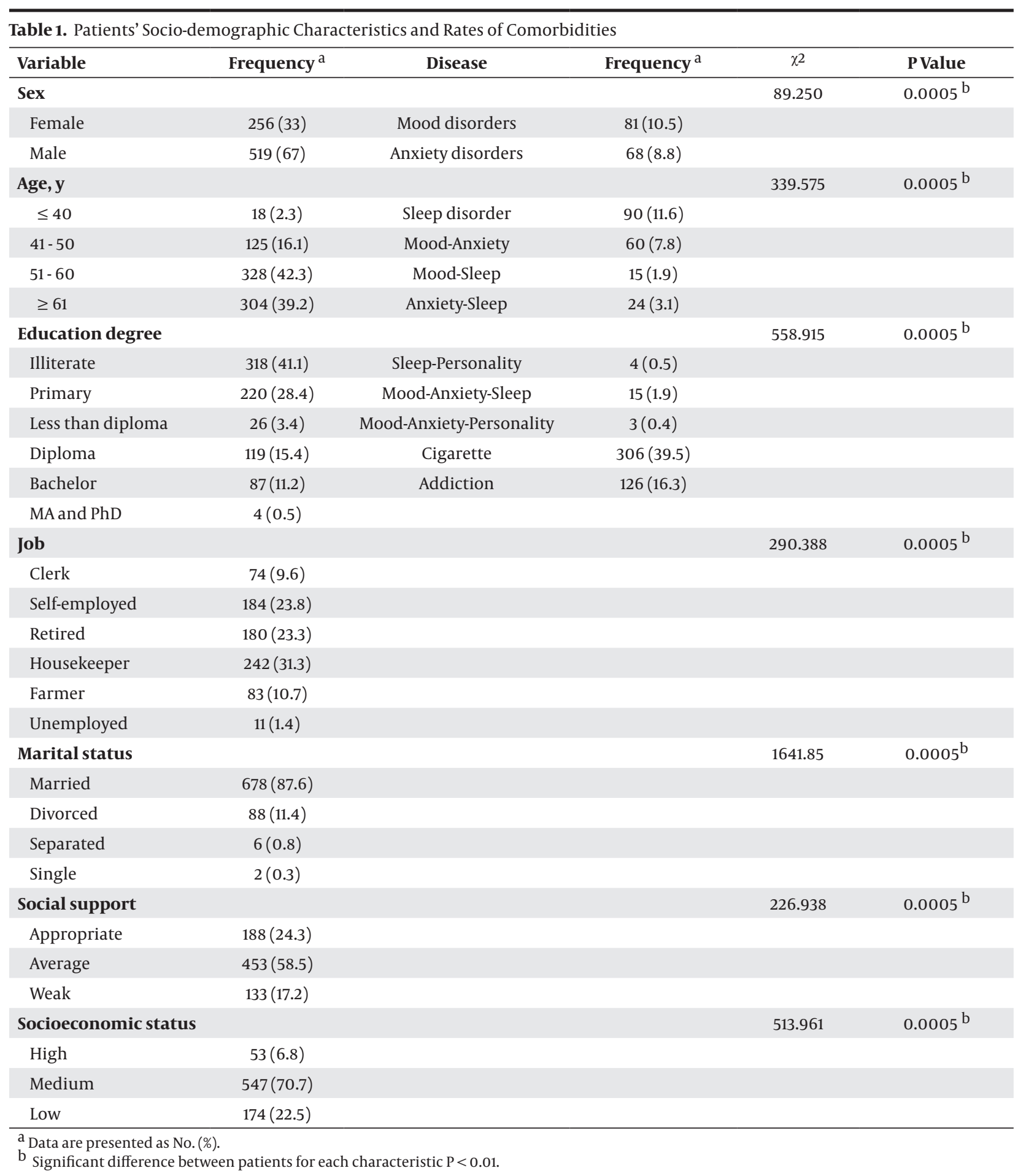

As indicated in Table 1, the men are twice as many women patients $\left(\chi^{2}=89.250, \mathrm{df}(1), \mathrm{P}<0.0005\right)$ and in terms of age, most patients are over fifty years old $\left(\chi^{2}=339.575\right.$, df (3), $\mathrm{P}$ $<0.0005)$. Also, there is a significant difference among the patients in terms of education degree $\left(\chi^{2}=558.915\right.$, df $(5), \mathrm{P}<$ 0.0005), job ( $\chi^{2}=290.388$, df (5), P $\left.<0.0005\right)$, marital status $\left(\chi^{2}=1641.85\right.$; df (3), $\left.\mathrm{P}<0.0005\right)$, social support $\left(\chi^{2}=226.938\right.$; $\mathrm{df}(2), \mathrm{P}<0.0005)$, socioeconomic status $\left(\chi^{2}=513.961, \mathrm{df}(2)\right.$, $\mathrm{P}<0.0005)$. Furthermore, the table shows that the rates of smoking and (39.5\%), substance abuse (16.3\%), sleep disturbances (11.6\%) and mood disorders (10.2\%) are high in the cardiac patients. Table 2 demonstrates the patients' attitudes about heart disease risk factors (biological, environmental, behavioral, and psychological). 
Saeidi M et al.

\begin{tabular}{|c|c|c|c|}
\hline Attitude & Frequency $^{\mathrm{a}}$ & $\chi^{2}$ & P Value \\
\hline Biologic & $61(4.3)$ & 820.356 & $0.0005^{b}$ \\
\hline Genetics & $61(4.3)$ & 6.025 & $0.014^{\mathrm{c}}$ \\
\hline Environmental & $56(3.8)$ & & \\
\hline War & $15(1.0)$ & & \\
\hline Smoke and toxic substances & $15(1.0)$ & & \\
\hline Dust & $20(1.4)$ & & \\
\hline Other people smoking & $6(0.4)$ & & \\
\hline Behavioral & $599(42.0)$ & & \\
\hline Lack of exercise & $44(3.1)$ & & \\
\hline Cigarette and substance abuse & $160(11.3)$ & & \\
\hline Nutrition & $188(13.3)$ & & \\
\hline Physical work & $56(3.9)$ & & \\
\hline Methadone & $2(0.1)$ & & \\
\hline Cholesterol & $48(3.3)$ & & \\
\hline Hypertension & $46(3.2)$ & & \\
\hline Diabetes & $41(2.9)$ & & \\
\hline Overweight & $8(0.5)$ & & \\
\hline Smoke bread & $6(0.4)$ & & \\
\hline Psychologic & $517(36.3)$ & & \\
\hline Stress and mourning & $391(27.5)$ & & \\
\hline Anger and rage & $101(7.4)$ & & \\
\hline Depression & $17(1.2)$ & & \\
\hline Spouse abuse & $4(0.2)$ & & \\
\hline Do not know & $148(10.4)$ & & \\
\hline Other & $47(3.3)$ & & \\
\hline
\end{tabular}

As Table 2 suggests, attitudes about behavioral risk factors account for $42.0 \%$ of this patients' beliefs. Then, the psychological factors (36.3\%), biological factors (4.3\%), and environmental factors (3.8\%) are ranked, respectively. Also, the rate of patients' unawareness of their illness (do not know) is $10.4 \%$ which is highly dubious, as the patients in this study experienced different treatment processes, and cardiac rehabilitation (which is the last phase of the treatment). However, after a lot of training by the medical team, the rate of patients' unawareness of the reasons of their disease can challenge the treatment processes governing the health and medical centers. It should be noted that $3.3 \%$ of the patients associated the cause of their disease with several problems, which are not included in this classification.

As can be seen in Table 2, the stress (27.5\%), which is considered as a psychological risk factor, ranks first among the beliefs of the patient; nutrition (13.3\%) and smoking
(11.3\%) have the next positions, respectively. The significant issue is unawareness of a large number of patients about the cause of their illness. The rate of unawareness included $10.4 \%$ of the patients, which is significant. Furthermore, as Table 3 suggests, there is a significant difference among the patients in term of four attitudes $\left(\chi^{2}=\right.$ 820.356; df (3); P < 0.01); and behavioral and psychological attitudes $\left(\chi^{2}=6.025\right.$; df $\left.(1) ; P<0.05\right)$. In fact, the patients identified the behavioral problems as the cause of their illness significantly.

Table 3 shows differences in attitudes with respect to socio-demographic variables. As can be seen, there is a significant difference between male and females in terms of attitudes toward the causes of disease with respect to socio-demographic variables. For example, it is know that women paying attention to psychological risk factors $\left(\chi^{2}\right.$ $=517.00, \mathrm{P}<0.0005)$; while men are more focusing on behavioral risk factors $\left(\chi^{2}=599.00 ; \mathrm{P}<0.0005\right)$ 
Table 3. Differences in Attitudes With Respect to Socio-Demographic Variables

\begin{tabular}{|c|c|c|c|c|c|c|c|c|c|}
\hline \multirow[b]{2}{*}{$\frac{\mathscr{e}}{\frac{\tilde{a}}{\tilde{n}}}$} & \multirow[b]{2}{*}{ 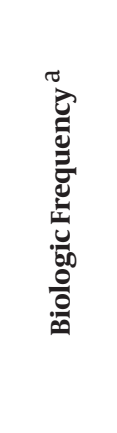 } & \multirow[b]{2}{*}{ 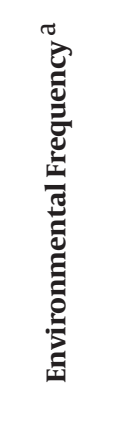 } & \multirow[b]{2}{*}{ 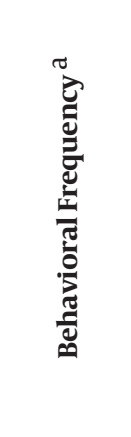 } & \multirow[b]{2}{*}{ 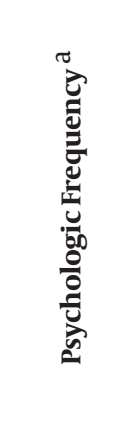 } & \multicolumn{4}{|c|}{$\chi^{2}$} & \multirow[b]{2}{*}{$\frac{\mathscr{g}}{\frac{\tilde{J}}{2}}$} \\
\hline & & & & & 宽: & 葛 & 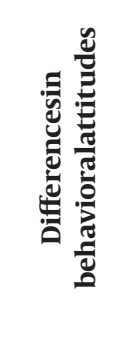 & 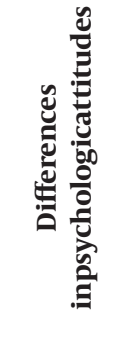 & \\
\hline Gender & & & & & 61.00 & 56.00 & 599.00 & 517.00 & 0.0005 \\
\hline Female & $16(4.2)$ & $20(5.3)$ & $139(36.3)$ & $206(53.7)$ & & & & & \\
\hline Male & $45(5.2)$ & $36(4)$ & $460(55)$ & $311(35.8)$ & & & & & \\
\hline Age,$y$ & & & & & 80.00 & 186.00 & 1800.00 & 1500.00 & 0.0005 \\
\hline$\leq 40$ & $4(13.4)$ & $1(3.3)$ & $11(36.7)$ & $14(46.6)$ & & & & & \\
\hline $41-50$ & $13(5.9)$ & $4(1.8)$ & $121(54.5)$ & $84(37.8)$ & & & & & \\
\hline $51-60$ & $19(3.7)$ & $21(3.9)$ & $269(50.1)$ & $227(42.3)$ & & & & & \\
\hline$\geq 61$ & $4(1)$ & $36(8.7)$ & $199(47.8)$ & $175(42.5)$ & & & & & \\
\hline $\begin{array}{l}\text { Education } \\
\text { degree }\end{array}$ & & & & & 164.00 & 248.00 & 3020.00 & 2500.00 & 0.0005 \\
\hline Illiterate & $5(1.2)$ & $33(7.2)$ & $226(49.1)$ & $196(42.5)$ & & & & & \\
\hline Primary & $10(3)$ & $15(4.5)$ & $180(54)$ & $129(38.5)$ & & & & & \\
\hline $\begin{array}{l}\text { Less than } \\
\text { diploma }\end{array}$ & $1(2.9)$ & $0(0)$ & $18(51.4)$ & $16(45.7)$ & & & & & \\
\hline Diploma & $8(4)$ & $8(4)$ & $103(49.5)$ & $89(42.5)$ & & & & & \\
\hline Bachelor & $17(10.5)$ & $5(3.1)$ & $73(44.7)$ & $68(41.7)$ & & & & & \\
\hline MA and PhD & $0(0)$ & $1(14.3)$ & $4(57.1)$ & $2(28.6)$ & & & & & \\
\hline Job & & & & & 82.00 & 248.00 & 2840.00 & 2490.00 & \\
\hline Clerk & $6(4.5)$ & $5(3.7)$ & $74(55.5)$ & $48(36.3)$ & & & & & \\
\hline Self-employed & $13(4.7)$ & $9(3.2)$ & $146(52.6)$ & $110(39.5)$ & & & & & \\
\hline Retired & $13(4.7)$ & $15(5.4)$ & $149(51.1)$ & $114(38.8)$ & & & & & \\
\hline Housekeeper & $9(2.3)$ & $17(5)$ & $123(36.5)$ & $188(56.2)$ & & & & & \\
\hline Farmer & $0(0)$ & $15(13.6)$ & $65(59.7)$ & $29(26.7)$ & & & & & \\
\hline Unemployed & $0(0)$ & $1(4.8)$ & $11(52.4)$ & $9(42.8)$ & & & & & \\
\hline $\begin{array}{l}\text { Socioeconomic } \\
\text { status }\end{array}$ & & & & & 82.00 & 124.00 & 1212.00 & 1000.00 & 0.0005 \\
\hline High & $5(6)$ & $3(3.4)$ & $46(55.1)$ & $30(35.5)$ & & & & & \\
\hline Medium & $30(3.7)$ & $42(5.1)$ & $394(47.4)$ & $365(43.8)$ & & & & & \\
\hline Low & $6(2.1)$ & $17(5.8)$ & $166(56.5)$ & $105(35.6)$ & & & & & \\
\hline
\end{tabular}

${ }^{\mathrm{a}}$ Data are presented as No. (\%).

\section{Discussion}

This study was designed to investigate the status of psychological risk factors among cardiac patients' attitudes. The results showed that the patients believed that the main cause of their illness is behavioral risk factors. Then, they referred to psychological, biological, and environmental factors, respectively. Also, significant percent of the patients were not aware of the cause of their illness. Consistent with the results of several studies $(12-14,16,17)$, 
the findings of this study suggest that cardiac rehabilitation patients considered psychological problems as the second important factor in the development of their disease. Meanwhile, stress and mourning, anger and rage, depression, and spouse abuse are of utmost importance. Furthermore, women paying attention to psychological risk factors as the most important factor in the development of their disease.

Evidence indicates (12) that there is a relationship between the attitudes of patients with their psychological and functional status regarding the patients' health which is associated with the behavior that originates from their knowledge (8), the patients' attitudes about the heart disease have a decisive role in their health behavior (9). The patients' attitudes and cognitions have a significant impact on the course of disease progression in all phases of disease experience, including understanding the signs, looking for a reason related to the disease, and changes in individuals' behavior (8). For example, patients with more myths have higher anxiety and lower physical function (12).

Researches show that there is a strong relationship between the patient's causal beliefs about cardiac disease, especially psychological factors, and its risk factors (14, 15). Psychological risk factors included worry, depression, and anxiety from the patients' perspectives (18). According to Lin et al. (19) the patients believe that stress is one of the most important factors of heart diseases and should always be avoided. Also, results of a study (17) showed that women identified stress as the main cause of their illness and these attitudes comprising the psychological stress are associated with both the patient's current mood and the reporting of their stressful life (14). Thus, improving patients' coping skills, by eliminating their dysfunctional beliefs (19) and establishing an effective therapeutic relationship, based on modifiable risk factors, may have impacts on causal beliefs and change the stressful lifestyle of patients (14).

van der Wal et al. (15) noted the acceptance and compliance with treatment recommendations related to the patients' knowledge and beliefs. Thus, increasing patients' knowledge and modifying their beliefs can positively affect the treating process (15) and increase psychological interventions acceptance by patients (7). Ignoring and neglecting the factors by members of the healthcare team lead to poor treatment efficiency. Hence, clinicians and health professionals should make people aware of psychological factors associated with heart disease that may affect heart disease prevention behaviors (23) and convince the patients that these factors are not out of control and the feeling of lack of control should not lead to neglecting and ignoring them (24). Thus, in order to increase the understanding of risk factors for heart patients and modification of their lifestyle and to have long-term and successful changes, it is necessary to create a common language between health professionals and patients (17).
Limitations of this study were the low level of education and higher age leading to tough interview process and a reduction in the therapeutic participation. Also, the results obtained by the study of patients referred to a rehabilitation center did not include those patients who did not go to rehabilitation after surgery. It is suggested that such studies should be done in stages before rehabilitation, for all the cardiac patients.

According to the patient's perceptions and attitudes, after the behavioral factors, psychological factors are the second cause of heart diseases. It is clear how to understand a heart disease and its related experiences by patients can affect the education and prevention of coronary heart diseases. Also, patients' attitudes play an important role in establishing effective therapeutic relationship, psychological adjustment, and compliance with treatment recommendations. Therefore, ignoring these factors by members of the medical teams may lead to a poor performance of the treatments. As these factors are controllable, learning to control and manage them can prevent the development of subsequent cardiovascular events.

\section{Authors' Contributions}

Mozhgan Saeidi participated in the design of the study, subject recruitment, data collection, data analysis and drafted the manuscript. Ali Soroush participated in the design of the study, and revised the manuscript critically for important intellectual content. Saeid Komasi participated in the design of the study, data analysis, and revised the manuscript critically for important intellectual content. Khodamorad Momeni revised the manuscript critically for important intellectual content. Behzad Heydarpour revised the manuscript critically for important intellectual content. All authors read and approved the final manuscript.

\section{References}

1. Buckley JP, Furze G, Doherty P, Speck L, Connolly S, Hinton S, et al BACPR scientific statement: British standards and core components for cardiovascular disease prevention and rehabilitation. Heart. 2013;99(15):1069-71.

2. Komasi S. The effectiveness of tow methods of relaxation and interpersonal cognitive problem solving (ICPS) on decreasing anxiety and depression in cardiac rehabilitation patients.Tonekabon: Islamic Azad university; 2010.

3. Department of health... Cardiovascular Disease Outcomes Strategy Improving outcomes for people with or at risk of cardiovascular disease.; 2013.

4. Sher L. Psychological Factors and Cardiovascular Disorders: The Role of Stress and Psychosocial Influences.: Nova Science; 2008.

5. Bath J, Bohin G, Jones C, Scarle E. Cardiac rehabilitation: A Workbook for Use with Group Programmes.Chichester: Wiley-Blackwell; 2009.

6. Capistrant BD, Gilsanz P, Moon JR, Kosheleva A, Patton KK, Glymour MM. Does the association between depressive symptoms and cardiovascular mortality risk vary by race? Evidence from the Health and Retirement Study. Ethn Dis. 2013;23(2):155-60.

7. Day RC, Freedland KE, Carney RM. Effects of anxiety and depression on heart disease attributions. Int J Behav Med. 2005;12(1):24-9. 
8. Hirani SP, Newman SP. Patients' beliefs about their cardiovascular disease. Heart. 2005;91(9):1235-9.

9. Lau-Walker M. Importance of illness beliefs and self-efficacy for patients with coronary heart disease. J Adv Nurs. 2007;60(2):187-98.

10. Emslie C. Women, men and coronary heart disease: a review of the qualitative literature. J Adv Nurs. 2005;51(4):382-95.

11. Wlodarczyk D. [Patients' beliefs about their illness and adaptation after myocardial infarction]. Pol Merkur Lekarski. 2004;17(97):81-4.

12. Furze G, Lewin RJ, Murberg T, Bull P, Thompson DR. Does it matter what patients think? The relationship between changes in patients' beliefs about angina and their psychological and functional status. J Psychosom Res. 2005;59(5):323-9.

13. Murphy B, Worcester M, Higgins R, Le Grande M, Larritt P, Goble A. Causal attributions for coronary heart disease among female cardiac patients. J Cardiopulm Rehabil. 2005;25(3):135-43.

14. Perkins-Porras L, Whitehead DL, Steptoe A. Patients' beliefs about the causes of heart disease: relationships with risk factors, sex and socio-economic status. Eur J Cardiovasc Prev Rehabil. 2006;13(5):724-30.

15. van der Wal MH, Jaarsma T, Moser DK, Veeger NJ, van Gilst WH, van Veldhuisen DJ. Compliance in heart failure patients: the importance of knowledge and beliefs. Eur Heart J. 2006;27(4):434-40.

16. Saeidi M, Komasi S, Soroush A, Zakiei A, Shakeri J. Gender Differences in Patients' Beliefs About Biological, Environmental, Be- havioral, and Psychological Risk Factors in a Cardiac Rehabilitation Program. J Cardio-Thoracic Med. 2014;2(4):215-20.

17. Astin F, Jones K. Heart disease attributions of patients prior to elective percutaneous transluminal coronary angioplasty. J Cardiovasc Nurs. 2004;19(1):41-7.

18. McCabe PJ, Barnason SA, Houfek J. Illness beliefs in patients with recurrent symptomatic atrial fibrillation. Pacing Clin Electrophysiol. 2011;34(7):810-20.

19. Lin YP, Furze G, Spilsbury K, Lewin RJ. Misconceived and maladaptive beliefs about heart disease: a comparison between Taiwan and Britain. J Clin Nurs. 2009;18(1):46-55.

20. Jankowski D. A Beginner's Guide to the MCMI-III.: American Psychological Association; 2002.

21. Choca JP. Interpretive guide to the Millon Clinical Multiaxial Inventory Washington.: American Psychological Association; 2004.

22. Blais MA, Holdwick DJ, McLean RY, Otto MW, Pollack MH, Hilsenroth MJ. Exploring the psychometric properties and construct validity of the MCMI-III anxiety and avoidant personality scales.J Pers Assess. 2003;81(3):237-41.

23. Tirodkar MA, Baker DW, Khurana N, Makoul G, Paracha MW, Kandula NR. Explanatory models of coronary heart disease among South Asian immigrants. Patient Educ Couns. 2011;85(2):230-6.

24. Darr A, Astin F, Atkin K. Causal attributions, lifestyle change, and coronary heart disease: illness beliefs of patients of South Asian and European origin living in the United Kingdom. Heart Lung. 2008;37(2):91-104. 